\title{
$\mathrm{O}$ rádio
}

\section{como aparato de comunicação Discurso sobre a função do rádio} BERTOLT BRECHT

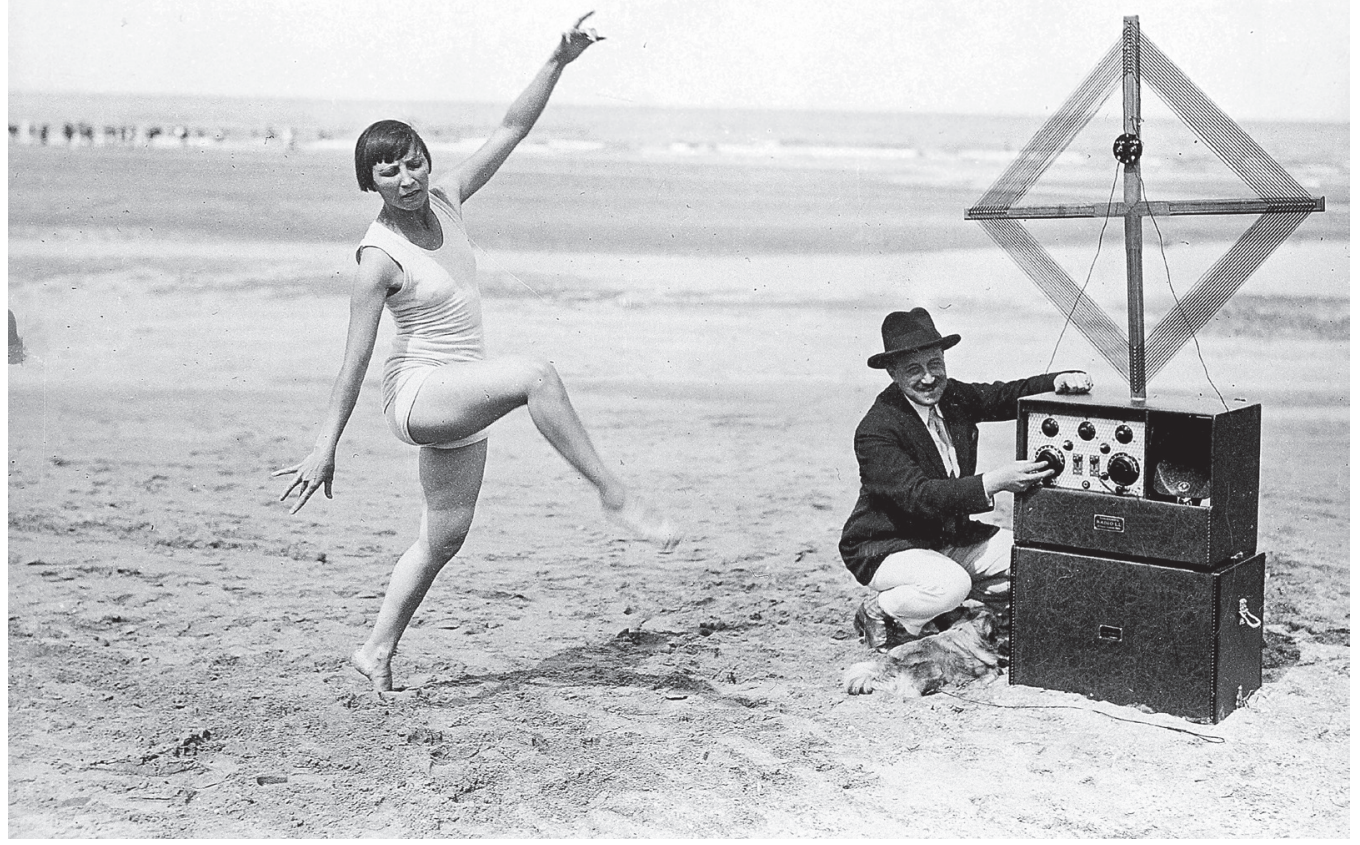

Bailarina do Teatro da Madeleine dança ao som do rádio na praia de Deauville, França, 1926.

\begin{abstract}
NOSsa organização social, que é anárquica - se é que se pode imaginar 1 uma anarquia da organização, ou seja, uma confusão mecânica e desproL vida de significados, largamente ordenada em torno da complexidade da vida pública -, a nossa organização social, nesse sentido, anárquica, possibilita que se façam e se desenvolvam invenções, que ainda estão por conquistar o seu mercado e por demonstrar a justificativa de sua existência; estamos falando, em resumo, de invenções que não são encomendadas. Assim, a técnica pôde adiantar-se a tal ponto que engendrou o rádio numa época em que a sociedade não estava madura para acolhê-lo. Não era o público que aguardava o rádio, senão o rádio que aguardava o público, e para melhor caracterizar a situação do rádio: não era a matéria-prima que esperava pelos métodos de produção com
\end{abstract}


base numa necessidade pública; eram os métodos de produção que procuravam ansiosamente pela matéria-prima. Tinha-se, repentinamente, a possibilidade de dizer tudo a todos, mas, pensando bem, não havia nada a ser dito. E quem seriam esses todos?

No começo, o homem contentou-se com a ausência de reflexão em torno do assunto. Ele olhava em torno de si, procurando por algum lugar onde algo era dito a alguém, e buscava imiscuir-se ali e, concorrencialmente, dizer algo a alguém. Foi esse papel de representante que o rádio desempenhou em sua primeira fase - representante do teatro, da ópera, da audição musical, de palestras, do café-concerto, da imprensa local etc.

Desde o início, o rádio imitou quase todas as instituições existentes que se relacionavam com a difusão do que era falado ou cantado: produziram-se confusão e atritos incontornáveis na construção de uma torre de Babel. Nesse armazém acústico, podia-se aprender a criar galinhas - em inglês e ao som do Coro dos Peregrinos - e a lição era barata como a água encanada. Essa foi a juventude dourada de nosso paciente. Não sei se ela já acabou, mas, se de fato acabou, esse jovem, que para nascer não teve de apresentar nenhum atestado de competência, terá de procurar, ao menos doravante, um objetivo na vida. É como o homem que se encontra em seus anos de maturidade, quando já perdeu a inocência, e que se pergunta para que, afinal de contas, ele está no mundo.

No que diz respeito a esse objetivo de vida do rádio, ele não poderá, em minha opinião, consistir simplesmente no embelezamento da vida pública. Para isso, ele não apenas já se revelou pouco adequado, como também a nossa vida pública mostra, infelizmente, pouca aptidão para ser embelezada. Não faço objeções à introdução de aparelhos receptores de rádio nos albergues dos desempregados e nas prisões (pensa-se evidentemente que, por seu intermédio, poder-se-á prolongar a baixo custo o tempo de vida dessas instituições), mas essa não pode ser a tarefa precípua do rádio, a de instalar receptores sob os arcos das pontes, mesmo quando ela traduz um gesto nobre, o de prover aqueles que irão passar a noite ali com o mínimo necessário, ou seja, com a apresentação dos "Mestres-Cantores". Aqui é preciso tato. Também, como método para restabelecer a afeição ao lar e possibilitar mais uma vez a vida em família, o rádio não é, até onde eu possa ver, suficiente, cabendo ainda perguntar se o que ele não pode alcançar seria, ao menos, desejável. Contudo, abstraindo-se a sua função duvidosa (quem muito traz acaba por nada trazer), o rádio tem uma face, quando deveria ter duas. Ele é um mero aparato de distribuição, ele simplesmente reparte algo.

E, agora, para ser positivo, ou, em outras palavras, para encontrar o que é positivo no rádio, apresento uma proposta para a modificação de seu funcionamento: o rádio deve deixar de ser um aparato de distribuição para se transformar num aparato de comunicação. O rádio seria o mais admirável aparato de comunicação que se poderia conceber na vida pública, um enorme sistema de canais; quer dizer, seria, caso ele se propusesse não somente a emitir, mas tam- 
bém a receber; ou, não apenas deixar o ouvinte escutar, mas fazê-lo falar; e não isolá-lo, mas colocá-lo numa relação. O rádio deveria, portanto, sair da esfera do fornecimento e organizar o ouvinte como fornecedor. Por isso, são absolutamente positivos todos os esforços do rádio quanto a imprimir nos assuntos públicos um caráter realmente público. O nosso governo precisa, tanto quanto a nossa justiça, dos serviços do rádio. Se o governo ou a justiça opõem-se a tais serviços do rádio, agem assim por receio e mostram que se ajustam somente à época em que não havia rádio, para não dizer à época que antecedeu a invenção da pólvora. Conheço tão pouco quanto os senhores as obrigações do primeiroministro; é função do rádio esclarecê-las para mim; entre essas obrigações dos altos escalões do governo, inclui-se a seguinte: fazer uso regular do rádio para inteirar a nação de suas atividades e da justificativa dessas atividades. A tarefa do rádio não se esgota, contudo, na transmissão desses relatos.

O rádio deve organizar, além disso, a recepção dos relatos, quer dizer, deve transformar os relatos dos governantes em respostas a questões dos governados. É missão do rádio possibilitar o intercâmbio. Ele, sozinho, pode promover as grandes discussões das empresas e dos consumidores sobre a normatização dos artigos de consumo, os debates em torno do aumento do preço do pão, as disputas nos municípios.

Se os senhores tomam isso por utópico, peço-lhes então que ponderem por que isso é utópico.

Não importando o que esteja a empreender, o esforço do rádio deve ser o de se contrapor à falta de propósito que torna risíveis quase todas as nossas instituições públicas.

Temos uma literatura despropositada, que não apenas se esforça por não ter nenhum propósito, como também se empenha ao máximo na tarefa de neutralizar os seus leitores na medida em que ela apresenta todas as coisas e situações sem as suas respectivas conseqüências. Temos institutos de formação inconseqüentes, que se esforçam ansiosamente por oferecer uma formação desprovida de quaisquer propósitos e que também não é a conseqüência de nada. Todas as nossas instituições formadoras de ideologia consideram que a sua principal tarefa é a de manter despropositado o papel da ideologia, em consonância com um conceito de cultura, segundo o qual a formação cultural já estaria concluída e a cultura não careceria de nenhum esforço criativo continuado. Não cabe aqui investigar em razão de que interesses essas instituições são inconseqüentes; mas, se um invento técnico, dotado de uma aptidão tão natural para as decisivas funções sociais, propõe-se um esforço tão desesperado para permanecer inconseqüente, envolvido no entretenimento mais inofensivo, então surge de modo incontornável a questão sobre a possibilidade de se defrontarem as forças da desconexão por meio da organização dos desconectados. Todo avanço nessa direção, por menor que seja, deveria produzir forçosamente um resultado natural, que ultrapassaria o efeito resultante de todas as realizações de caráter simplesmente culinário. Toda campanha com um programa definido, ou seja, toda campanha 


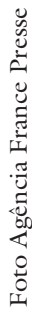

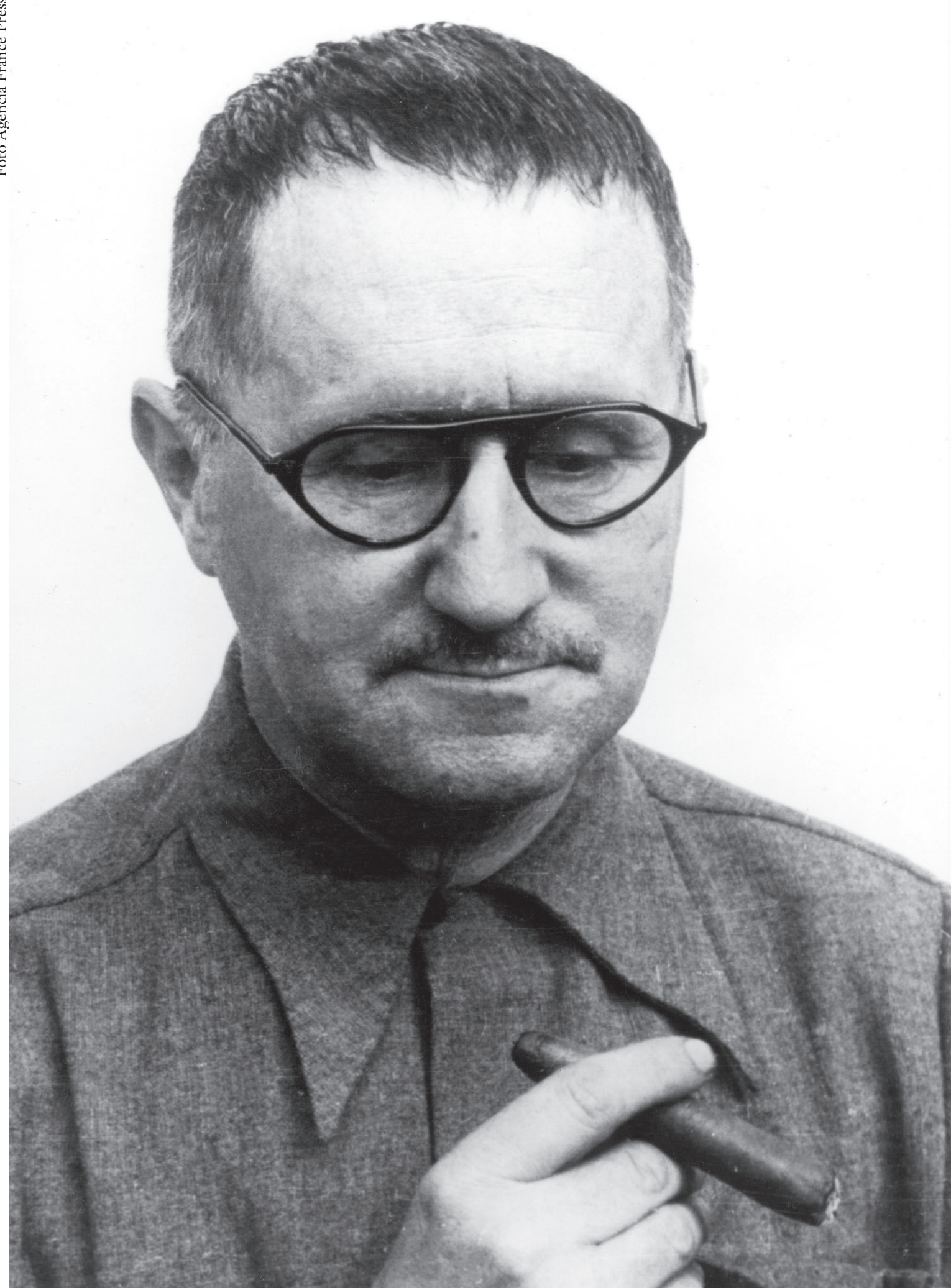

Para B. Brecht, o rádio deveria sair da esfera do fornecimento e organizar o ouvinte como fornecedor. 
que intervém efetivamente na realidade, que tem por objetivo a mudança da realidade, mesmo que em pontos de menor importância, como a destinação que se deva dar aos prédios públicos, garantiria ao rádio uma atuação incomparavelmente mais eficaz e lhe conferiria um significado social totalmente diverso se comparado com a sua atual postura meramente decorativa. No que diz respeito à técnica que se desenvolve em todos esses empreendimentos, ela se pauta pela tarefa principal de permitir que o público não apenas seja ensinado, mas que ele também ensine.

Atribuir um caráter interessante a esses empreendimentos educativos, ou seja, tornar interessante o que interessa, constitui uma tarefa formal do rádio. Ele pode realizar artisticamente uma parte disso, especialmente a parte destinada à juventude. Ao encontro desse empenho do rádio em configurar artisticamente aquilo que se ensina, viriam então os esforços da arte moderna, os quais almejam emprestar um caráter educativo à arte.

Como exemplo desses possíveis exercícios que se utilizam do rádio como aparato de comunicação, fiz comentários, na semana musical de Baden-Baden, de 1929, sobre o "Vôo de Lindbergh". Esse é um modelo para um novo emprego do aparato dos senhores. Um outro modelo seria a "Peça didática de Baden sobre o entendimento". Trata-se da parte ${ }^{1}$ pedagógica desempenhada pelo "ouvinte": a da tripulação do avião $e$ a da multidão. Ele se comunica com a parte do coro instruído, dos clowns e do enunciador apresentados pelo rádio. Atenho-me propositadamente à discussão de princípios, porque a confusão no âmbito da estética não é a causa da confusão sem precedentes na sua função fundamental, senão o seu resultado. Não se pode, por meio do juízo estético, eliminar a confusão - uma confusão muito útil para alguns - em torno da verdadeira função do rádio. Posso dizer-lhes que o emprego dos conhecimentos teóricos do teatro moderno, isto é, do teatro épico, haveria de produzir resultados muito auspiciosos.

Nada é menos adequado que a velha ópera, a qual objetiva a produção de situações extáticas, pois ela depara no ouvinte o homem isolado, e dentre todos os excessos alcoólicos nenhum é mais pernicioso que a embriaguez taciturna.

O velho drama da dramaturgia shakespeariana é, também, praticamente inútil no rádio, pois diante do espectador não é a multidão, é o sujeito só e isolado que é levado a investir sentimentos, simpatias e esperanças em intrigas cujo único objetivo é ensejar ao indivíduo dramático a oportunidade de se expressar.

O teatro épico, com o seu caráter numérico, com a separação dos elementos, quer dizer, com a separação entre imagem e palavra, e entre as palavras e a música, e, particularmente, com a sua postura didática, teria a oferecer ao rádio uma infinidade de sugestões práticas. Contudo, o seu emprego meramente estético, assim como uma nova moda, de nada serviria, e de velhas modas já estamos fartos! Se a instituição teatral se dedicasse ao teatro épico, à representação 
pedagogicamente documentária, então o rádio poderia desenvolver uma forma absolutamente nova de propaganda para o teatro, isto é, poderia desenvolver informação real - uma informação imprescindível. Um comentário assim, intimamente ligado ao teatro, um valioso e legítimo complemento do próprio drama, poderia desenvolver formas inteiramente novas. Seria ainda possível organizar um trabalho conjunto das organizações teatrais e radiodifusoras. $\mathrm{O}$ rádio poderia transmitir o coro ao teatro, bem como levar ao espaço público as decisões e produções oriundas da vontade do público que se reuniu em organizações coletivas das peças didáticas etc.

Não vou discorrer sobre esse etc. De propósito, não vou falar das possibilidades de separar a ópera do drama, e ambos do rádio, ou solucionar semelhantes questões estéticas, embora eu saiba que os senhores talvez esperem isso de mim, uma vez que os senhores tencionam vender a arte por meio de seu aparato. Mas, para ser vendável, a arte, hoje, precisa primeiro ser comprável. E eu prefiro não lhes vender nada; quero tão-somente formular a proposta fundamental em torno da transformação do rádio num aparelho de comunicação da vida pública. Isso é uma inovação, uma proposta que parece utópica e que eu mesmo caracterizo como utópica quando digo: o rádio poderia, ou o teatro poderia; sei que as grandes instituições não podem fazer tudo aquilo que seriam capazes de fazer, também não podem tudo o que querem. Elas desejam ser abastecidas por nós, ser renovadas, mantidas vivas por meio de inovações.

Não nos cabe, contudo, absolutamente, restaurar por meio de inovações as instituições ideológicas, que têm por base a ordem social vigente. Cabe-nos, antes, levá-las à entrega de sua base por meio de inovações. Assim sendo, pelas inovações! Contra a restauração! Por meio de propostas que sempre avançam e nunca cessam, visando promover um melhor emprego do aparato em razão do interesse público, temos de abalar a base social desse aparato, e desacreditar o seu emprego em função do interesse de poucos.

Irrealizáveis nessa ordem social, realizáveis numa outra, essas propostas, que constituem apenas uma conseqüência natural do desenvolvimento técnico, servem à propagação e formação dessa outra ordem.

Nota

1 Parte, na acepção de componente de uma composição musical, nesse caso, de uma das vozes de um coro. (N.T.)

Bertolt Brecht, poeta e dramaturgo alemão, nasceu em Augsburg, Alemanha, em 1898, e morreu em Berlim, em 1956.

Tradução de Tercio Redondo. O original em alemão - Der Rundfunk als Kommunikationsapparat - encontra-se à disposição do leitor no IEA-USP para eventual consulta. 